\title{
Designing Virtual Avatars to Empower Social Participation among Older Adults
}

\section{Romina Carrasco}

Microsoft Research Center for

SocialNUI

The University of Melbourne,

Melbourne, Australia

rcarrasco@student.unimelb.edu.au
Permission to make digital or hard copies of part or all of this work for personal or classroom use is granted without fee provided that copies are not made or distributed for profit or commercial advantage and that copies bear this notice and the full citation on the first page. Copyright for third-party components of this work must be honored. For all other uses, contact the Owner/Author.

Copyright is held by the owner/author(s).

CHI'17 Extended Abstracts, May 06-11, 2017, Denver, CO, USA ACM 978-1-4503-4656-6/17/05.

http://dx.doi.org/10.1145/3027063.3027133

\begin{abstract}
Social participation among older adults improves quality of life, reducing negative emotions that may lead to depression or premature death. The use of virtual avatars (self representations of the user) in online environments can support social participation by providing opportunities for enjoyment. These new online self-representations can affect the behavior of users in both the digital and the physical world.

However, further study is needed to identify how to promote social participation for older adults through appropriate design of avatars.
\end{abstract}

\section{Author Keywords}

Older adults; virtual reality, virtual avatars; social participation; online games.

\section{ACM Classification Keywords}

H5.1 [Multimedia Information Systems]: Artificial, augmented and virtual realities.

\section{Context and Motivation}

The proportion of the older population is growing worldwide. One of the repercussions of this demographic change is that some older adults are experiencing low levels of social participation, which 
can be caused by mobility or sensory impairments, geographical isolation or family circumstances [5] Social participation can be beneficial for older people bringing positive health consequences. Despite the barriers, Information Communication Technologies could be used to promote this connectedness [5]. While the low percentages of older adults participating in online social networks suggest that they do not replicate the interests and behaviors of younger populations [2], this conduct may also suggest that some older people perceive a difficulty when using input devices as a keyboard and a mouse to generate written conversations [3]. On the other hand, the increasing participation of older adults in online gaming [1] may be addressing these problems. Virtual reality brings interesting opportunities that overcome the limitations of text-based environments and can use domestic gaming technologies that can be useful for ageing populations. Older adults' participation in these environments can be done through an avatar, a visual animated representation of the person controlled by the user in real time. This digital body has characteristics that can facilitate social behavior as it is enriched with gestures, voice and body language that promote more natural ways of expression. Furthermore, these visualizations of the body allow the users to project and explore their identity in an experimental way. The way avatars look may change the social behaviors of the users [6]. In a study conducted in virtual environments older participants preferred to design avatars that were ageless allowing them to socialize with younger populations [4]. In addition, emerging technologies, such as the Microsoft Kinect, which uses a depth camera to recognize and represent whole body movements, offer new ways of representing and controlling avatars online. Despite the potential for avatars to contribute to the social lives of older people, to date, little research has been conducted that explores older peoples' use of avatars. It is this gap in the literature that my research aims to address.

\section{Research Question}

The main research question of this thesis is: "What role do avatars play in empowering tech-based social participation for older adults?"

Avatars are common in gaming environments and considering that older adults are playing different kinds of online games (not just those that involve visual animated avatars), the first study will broadly examine the concept of self-representation in older adults' online gaming. The analysis will include names, static images, or animated graphics that older adults choose to represent their identity in the game environment. Studying these forms of self-representation will provide lens to examine the factors connected to social interactions in online gaming.

The research is divided into three research questions (RQ); each corresponding to a study outlined in the methods section. RQ1. How are older adults using online games for socializing? RQ2. What are the design considerations of avatars to promote social participation in older adults? RQ3. How can avatars empower social participation in older adults using the developed technology?

\section{Hypothesis}

The hypothesis of this research is that avatars (visua animated representations of the person controlled by the user in real time) are a useful tool in promoting social participation among older adults (65+). 


\section{Research Methods}

Study 1: Selfrepresentations of Older Adults in Online Games Data Collection: In-depth semi-structured interviews and observations of gameplay behavior.

Data Analysis: Case study and thematic analysis.

Study 2: Co-designing avatars with Older Adults

Participatory design workshops

Data Collection: observations, semi-structured interviews and focus groups.

Data Analysis: Thematic analysis.

\section{Study 3: Exploring the potential of Avatars empowering Social} Participation in Later Life Field Deployments; Data Collection: observations, semi-structured interviews. Data Analysis: Thematic analysis.

Table 1: Overview of the research methods of each study of the investigation

\section{Methods}

This research will use qualitative methods (detailed in Table 1) firstly to generate a holistic understanding of current practices of older adults playing online games with other people. Secondly, a participatory design workshop will identify further design opportunities to create configurable avatars that promote social participation. Based on these insights, we will create a prototype to evaluate our hypothesis in a final field deployment.

In response to my first research question, I started recruiting older adults $(65+)$ who play online with other people and live in Victoria, Australia, using a combination of online and offline advertising and snowball sampling. Advertisements were published in online forums of gamers (12), older adults (6), aged care industry (3) and 7 online social networks at Victoria. Additionally, I have given 4 talks, sent 39 emails and posted 60 flyers to advertise the study. The efforts for recruiting will continue until we have 12 participants or achieve data saturation.

\section{Results of Study 1: Self representations of Older Adults in Online Games}

Three participants between the ages of 74 and 81 who play daily online games with other people have been interviewed to date. In this section, I provide a description of each single case using pseudonyms, followed by a process of thematic analysis identifying relevant topics to the research question.

Albert is a 76-year-old man who has been playing online games daily during the last 3 years. He plays Words With Friends on his iPad with his wife and occasionally with friends he already knows. He declared that the distance is not a problem as "...If it happen to be 300 miles away ... we still play". When playing, Albert uses the name of the place where he used to live until he retired as this self-representation reminds him of home. Albert prefers to have time and not finish the game in one session, affirming: "we might take a couple of days or sometimes even a week".

Belinda is a 74-year-old woman who plays online games most nights. She plays Words With Friends with her husband stating that "... it is a little risky playing with people you don't know..." However, she believes the game provides opportunities to have close social relationships. One of her friends made a new friendship through online games that has lasted for more than three years. For self-representation, she uses the name of the farm where she used to live mentioning that everybody uses nicknames and not their real name.

Craig is an 81-year-old man who plays Battlefield for 6 hours a day on his desktop computer (Figure 1). While he believes playing with other people is "much better" as you can chat to them (using voice to communicate) and "stare at them", he mentioned that he does not like playing with younger gamers who have different interests and do not play fair. He started playing online games in 2000 and in 2003 joined The Older Gamers.com (TOG), an online community for players over 25 years old. Craig had made many friends through the game and even some of his friendships have transferred to the physical world as illustrated by gifts and visits he has received over the years from players he met online. Craig's player nickname uses the prefix "TOG", an acronym of the name of the forum in which he participates. In the game, he uses the name of a famous wrestler he used to admire when he was 


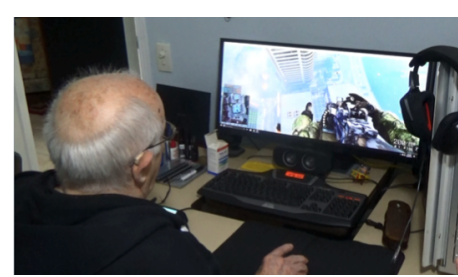

Figure 1. Craig playing Battlefield in his desktop computer younger. When selecting his avatar, he mainly chooses to be "support" as this character makes him feel in less risk as it has a shooting role, an activity which he was very good at when he was younger.

Although not all these cases provide information about the use of avatars by older adults, they do show that the way players represent themselves online is important. As they are linking their self-representations to nostalgic elements of their past that may be reinforcing their identity in a dynamic negotiation between who they are, who they were and who they want to be. In this same way, for Craig the avatar empowers him to practice and enjoy an activity he likes and may not be able to practice anymore in the physical world. On the other hand, online games may support social participation. Even those who played online with their partners affirmed that playing caused social interactions outside the game. For the third participant, these interactions may be providing a sense of group identification that is depicted in his selfrepresentation by using the name of the forum as part of his player nickname. Finally, the possibilities that

\section{References}

1. Brand J. and Todhunter, S. 2015. Digital Australia 2016. Eveleigh, NSW: IGEA

2. Charness, N., \& Boot, W. R. 2016. Technology, Gaming, and Social Networking. In Handbook of the Psychology of Aging. Elsevier Inc. http://doi.org/10.1016/B978-0-12-4114692.00020-0

3. Castilla D, A Garcia-Palacios, J Bretón-López. 2013. Process of design and usability evaluation of a telepsychology web and virtual reality system for avatars have for promoting social participation among older adults might be better understood through a comment of Craig. It may be because he plays with avatars that he made an allusion to be "staring" to other gamers while playing, suggesting the kind of body language he perceives in the game. This ability to incorporate more natural ways of interactions suggests how avatars can enrich social relationships.

\section{Expected Contributions}

This research expects to make the following contributions: (1) provide evidence of the role that digital self-representations play to support socialization among older adults playing online games. (2) Illustrate the design opportunities of avatars and virtual environments to empower social participation among older adults. (3) Finally, influence governments and organizations that are looking for initiatives to promote social participation among older adults.

\section{Acknowledgements}

Assistance provided by Prof. Frank Vetere, Dr. Jenny

Waycott and Dr. Steven Baker was greatly appreciated.

the elderly: Butler. International Journal of HumanComputer Studies 71, 3: 350-362.

4. Siriaraya, P., Ang, C. S., \& Bobrowicz, A. 2014. Exploring the potential of virtual worlds in engaging older people and supporting healthy aging. Behaviour \& Information Technology, 33(3), 282293. http://doi.org/10.1080/0144929X.2012.691552

5. World Health Organization. 2015. World report on ageing and health. Geneva, Switzerland.

6. Yee, N. 2014. Proteus paradox : how online games and virtual worlds change us, and how they don't. New Haven : Yale University Press. 


\section{University Library}

\section{- M M N E R VA A gateway to Melbourne's research publications}

Minerva Access is the Institutional Repository of The University of Melbourne

Author/s:

Carrasco, R

Title:

Designing Virtual Avatars to Empower Social Participation among Older Adults

Date:

2017

Citation:

Carrasco, R. (2017). Designing Virtual Avatars to Empower Social Participation among Older Adults. Proceedings of the $2017 \mathrm{CHI}$ Conference Extended Abstracts on Human Factors in Computing Systems - CHI EA '17, ACM Press. https://doi.org/10.1145/3027063.3027133.

Persistent Link:

http://hdl.handle.net/11343/242029 